\title{
Análisis Comparativo en la Logística y Sostenibilidad de Puertos El Callao y Cartagena de Indias
}

\section{Comparative Analysis of the Logistics and Sustainability of the Ports of El Callao and Cartagena de Indias}

Teófilo O. Boyano-Fram

Universidad Libre - Colombia

ORCID iD: https://orcid.org/0000-0002-5373-4644

Teofiloo.boyanof@unilibre.edu.co
Fecha de recepción: 19/02/2021

Fecha de evaluación: 21/03/2021

Fecha de aceptación: 28/05/2021

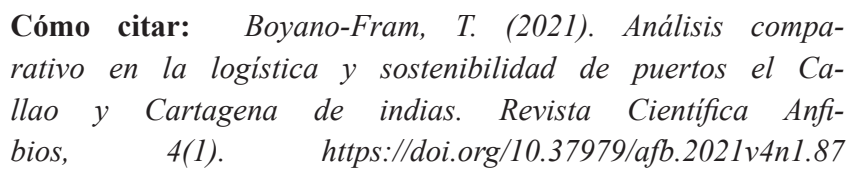

\section{Resumen}

En tiempos de crisis el aprovisionamiento no puede detenerse por seguridad alimentaria y sostenibilidad empresarial, el covid y futuras pandemias tendrán impacto en el mundo, pero las relaciones comerciales siguen y el abastecimiento también, este artículo se hizo mediante la recopilación de datos y referentes que existen entre los dos Puertos en América del Sur y son El Puerto del Callao en Perú y el Puerto de Cartagena de Indias en Colombia, se entrevistó a expertos en el tema, revisión de revistas especializadas y los informes que arrojan las entidades a su cargo, también se tuvo en cuenta: la sostenibilidad de los Puertos, su movimiento portuario y la logística portuaria, la intención es observar su relación que se da entre el crecimiento del Puerto y la ciudad, en él se concluye que ambos puertos contribuyen a la economía del Continente y que presentan asimetrías por su georreferenciación y vocación con su entorno económico y social.

\section{Palabras clave}

Puerto; sostenibilidad; logística; mercancía; contenedores; seguridad e infraestructura

\begin{abstract}
In times of crisis the supply cannot be stopped for food security and business sustainability, the covid and future pandemics will have an impact on the world, but trade relations continue and so does the supply, this article was done by collecting data and references that exist between the two ports in South America and are The Port of Callao in Peru and the Port of Cartagena de Indias in Colombia, we interviewed experts on the subject, reviewing specialized journals and reports that are issued by the entities in charge, was also taken into account: the sustainability of the Ports, its port movement and the port logistics, the intention is to observe its relation that is given between the growth of the Port and the city, in it is concluded that both ports contribute to the economy of the Continent and that they present asymmetries by their georeferentiation and vocation with their economic and social surroundings.
\end{abstract}

\section{Keywords}

Port; sustainability; logistics; merchandise; containers; security and infrastructure 


\section{Introducción}

El año 2020 pasará a la historia como el año de los retos, no sólo por la pandemia que ha afectado en gran parte a Europa, África, Asia, América y el resto del mundo, sino por la supremacía de los mercados mundiales y la competencia en dominar nuevos mercados, todo país desea aumentar sus fronteras para abastecimiento y abastecer a los demás. Esta es un estudio de carácter descriptivo y de corte cualicuantitativo, enmarcado en el paradigma de las ciencias sociales, específicamente dentro de la Administración y la gestión portuaria, se apoya en textos por lo que también se asocia a estudio bibliométrico, ya que se revisan gran cantidad de artículos, revistas especializadas en el tema y entes reconocidos que hacen estudios en materia de sostenibilidad y portuaria. Entrevistas a personas versadas, observación estructurada relacionada con datos estadísticos y cuadros recopilados del movimiento portuario y revisión de la sostenibilidad de la ciudad. Los Puertos revisten gran importancia para las maniobras logísticas, su movimiento da un referente para tenerlo en cuenta para canalizar mercancías o tenerlo como una opción de transbordo en caso de un inconveniente o que esté en el itinerario de las mercancías para el aprovisionamiento; si no están preparados, podrían bajar puntos en competitividad, desestimular a inversionistas en colocar negocios, no tenerlo en cuenta para turismo de cruceros y perdería las externalidades positivas que su gestión ocasiona. Es por eso por lo que se hace el siguiente interrogante, ¿Cómo se puede analizar los Puertos del Callao y Cartagena de Indias que permita corroborar su sostenibilidad en su entorno y la región?

\section{Antecedentes}

Ambos puertos según la historia son considerados heroicos, Cartagena por gestar la independencia en el año de 1811 y el Callao por ser la zona que Perú utilizó para sellar su independencia, en cuanto al Puerto de Cartagena son más de 487 años de historia, su situación geográfica como Puerto natural debido a una Bahía de aguas tranquilas, y dos bocas de entrada para las embarcaciones, se le diseñó una especie de escollera submarina para evitar la entrada de Piratas y Bucaneros, y aunque varias veces cañoneada y vuelta a construir, sólo tiene una entrada activa en el Caribe, la otra entrada es la boca grande que no se utiliza por su bajo calado, al abrirlo o dragarlo podría afectar varios Edificios del sector turístico de Cartagena, aunque hay otra que se diseñó al unir varias lagunas y es la del Canal del Dique que sería su entrada fluvial hacia la zona andina y pueblos ribereños del Caribe, irriga gran parte del suroriente del departamento de Bolívar en su trayectoria por donde pasa el Rio Magdalena hacia Bocas de Ceniza muy cerca de Barranquilla.

Cartagena luego de tantos ataques y gracias a Don Blas de Lezo que en tiempos de las conquistas de nuevos mundos resistió varios de ellos, especialmente por parte de los ingleses, piratas y corsarios, posteriormente gracias a los saqueos se sabe que al menos a uno de ellos se le dio título nobiliario de Sir, como Francis Drake. Cartagena de Indias no se rindió ante los grandes ataques y aunque varias veces quedó asolada, muchos productos pasaron por su Puerto desde oro y muchas de las reliquias indígenas, hasta africanos que llegaron a un mundo que no pudieron regresar y contar. La Ciudad Heroica, varios siglos después y a principios del Siglo XIX es cuando gesta su independencia y no recibe apoyo de Santa fe de Bogotá, lo hizo en el año de 1811, el mes 11, del día 11 (algunos sostiene que a las once); fue el tiempo de la firma del Bando, el cual es fue una diatriba hacia la Corona Española por sus impuestos, atropellos y descuido de su administración, posteriormente, es decir en el año de 1815 viene la retoma de la ciudad llamado el Sitio de Morillo, es el año de 1815, luego de 115 días de sitiada y hambrienta, un 5 de diciembre de ese 1815 se abre sus puertas y fusilan a los últimos insurrectos, en el Camellón que pasó a llamarse el Camellón de los Mártires, a escasos metros de la Bahía de las Ánimas donde hoy se ubica aledaño el Centro de Convenciones de Cartagena, hoy llamado Julio Cesar Turbay Ayala. Pasaron más de 80 años y la Presidencia de un ilustre cartagenero Rafael Núñez Moledo, hijo de un Coronel fue más de 4 veces Presidente de Colombia, la última ocasión al ser reelegido renunció por su avanzada edad; vale la pena recordar que muchos años antes de la llegada de Rafael Núñez, el Puerto de Cartagena tuvo su última escaramuza el 24 de junio de 1821, cuando el Almirante José Prudencio Padilla, asaltó las últimas embarcaciones realistas en las inmediaciones de la Bahía de las Ánimas, cerca al hoy muelle turístico, apresó 11 embarcaciones incluyendo su material de guerra; ocasionó la huida del Virrey Juan Sámano a Pa- 
namá y la capitulación del brigadier Torres y Velasco, mediante la firma en el mismo año de 1821 el10 de octubre; por lo que se corrobora la afinidad histórica, portuaria y cultural con el Puerto del Callao, el tema concerniente a lo cultural se abordará más adelante.

La ciudad creció en empresas a principios del Siglo XX en ventas de carne, cervezas y productos de aseo, Meisel-Roca, A. (1999) sostiene que al mismo tiempo se dio un derrumbe sistemático de las murallas, especialmente la que va desde el Reloj Público hasta la India Catalina, para acabar con los embates del mar en Marbella, hasta el año de 1924, la Ley 32 que prohibió cualquier derrumbe de murallas en la ciudad, mientras la ciudad tuvo textilera y empresas de confecciones. Liderazgo en gaseosas como la Kola Román y perfumería como la de los Lemaitre y la gran fábrica de papeles Mogollón que dejó productos casi hasta los años $80 \mathrm{~s}$.

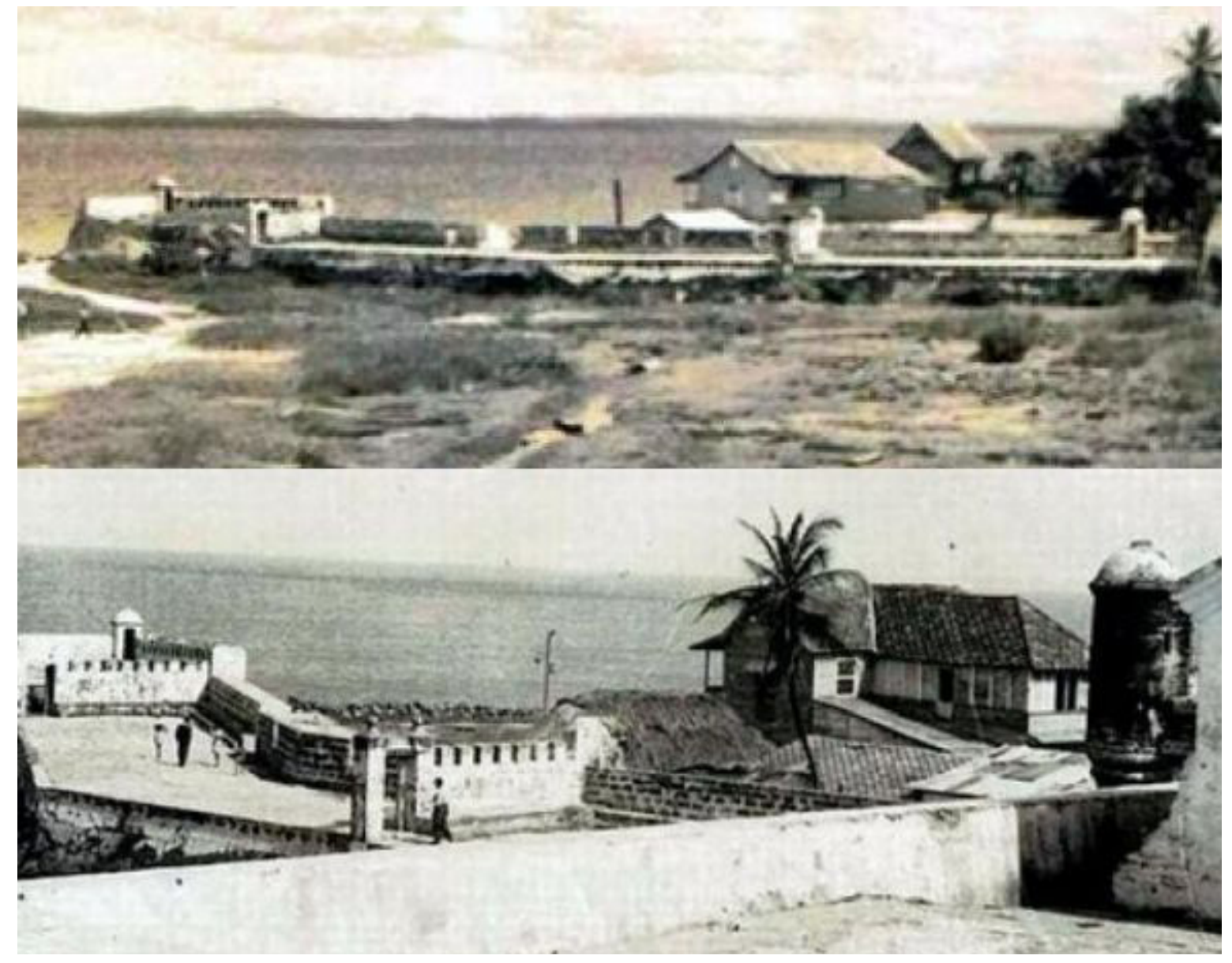

Tomada en el año de 1925; En laguna del Cabrero se encontraba ubicada la Fábrica de tejidos de La Espriella.

Imagen 1. Laguna del Cabrero

Fuente: cartagenadeindiasweb.com (2011).

Esta es una de las fábricas de tejido que floreció en Cartagena de Indias, con el paso del tiempo la ciudad crecía y comerciaba hasta Calamar que era un gran Puerto Fluvial y hubo la necesidad de construir un tren. Por eso operó desde el año de 1894 hasta el año de 1951, era una ruta ferroviaria que tenía como objetivo unir el Rio Magdalena que pasaba por Calamar, hasta Cartagena, pasando por: Soplaviento, Arenal,
Arjona y Turbaco, hasta llega a Cartagena, se cree que por el acceso al Centro Histórico hubo que quitar una parte de la Muralla de la Matuna, otros dicen que fue por cuestiones de salubridad y el inmenso calor y hacinamiento que tenía la ciudad, lo cierto es que parte de la muralla, el tren y el Canal llamado San Anastasio dejaron de existir con el progreso y el desarrollo turístico de la ciudad. 


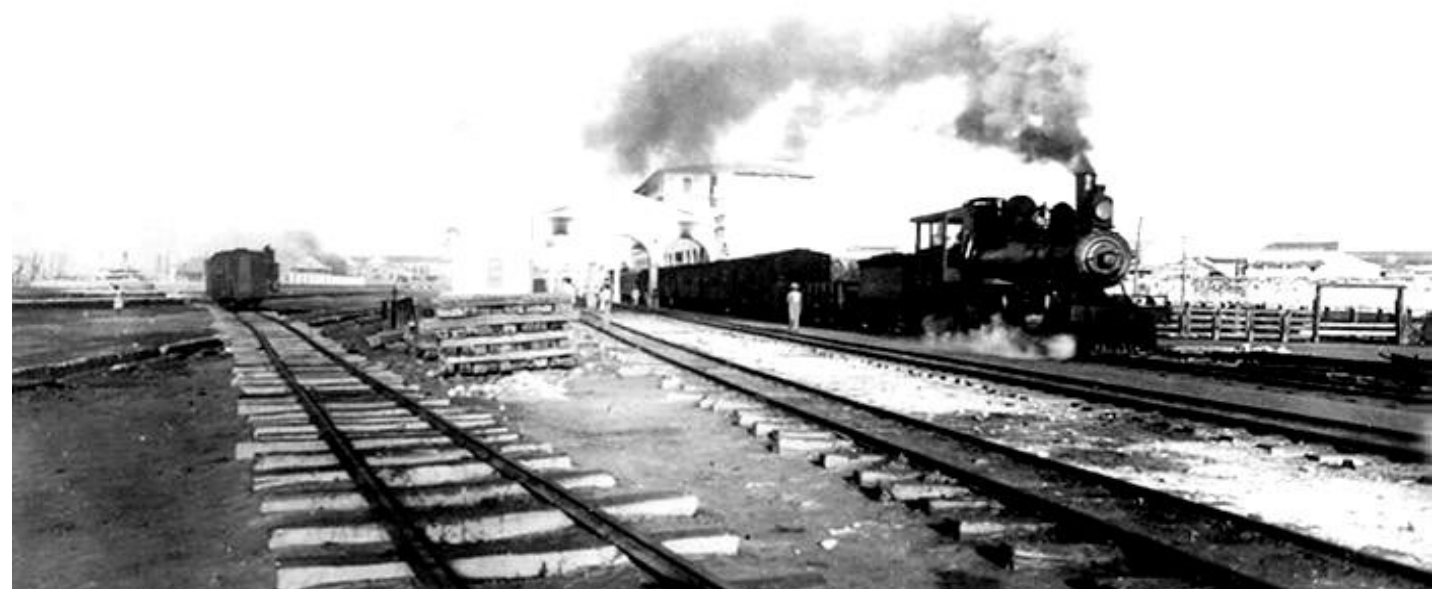

Imagen 2. El Tren de Calamar y su ruta a Cartagena de Indias a mediados del Siglo XX Fuente: Revista Contestarte (2017)

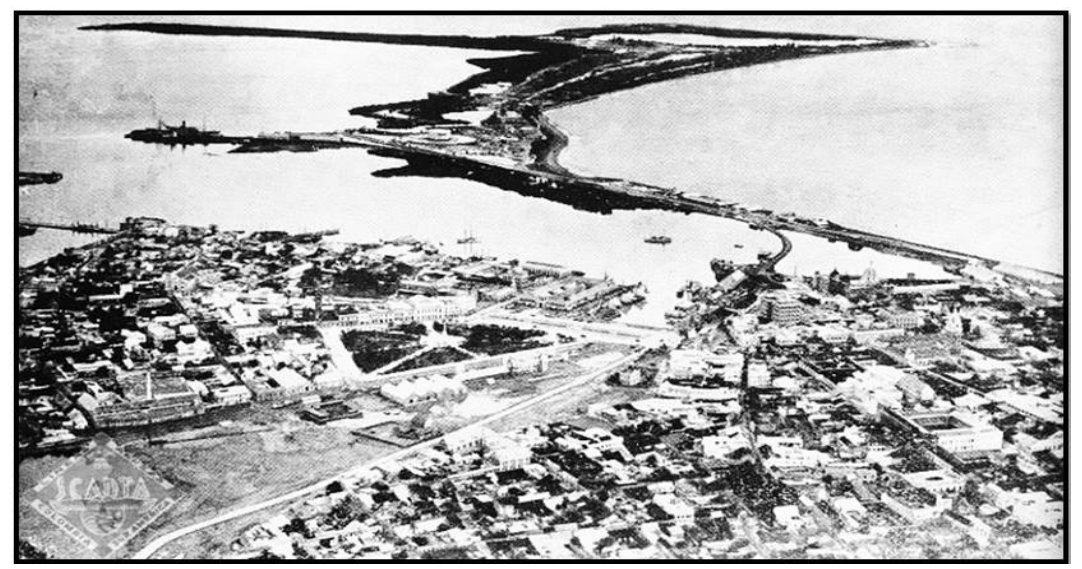

Imagen 3. La península de Icacos (Bocagrande) Fuente: Scadta (1928)

El Puerto de Cartagena a nivel de América está de 4 y el Puerto de Callao está 6, separados por el Puerto de Panamá. antes, cuando estaban en manos del público o eran Puertos estatales, su rendimiento era menor y más demorada la maniobra logística, cada vez las exigencias del mercado global crecen en certificaciones, inversión en infraestructura, tiempos y movimientos que soporten la afluencia de mercancías y calidad de servicio y capacitación de su Talento Humano, sino se tiene en cuenta lo anterior los Puertos comienzan a perder protagonismo, las navieras $\mathrm{y}$ agencias comienzan a buscar otros rumbos y traerían serios problemas sociales a los Puertos y de tipo económico, ya que la gran inversión y el financiamiento no permitiría recuperar esos compromisos monetarios.
Cartagena de Indias, ya para el año 2014 movilizaba más de 20 millones de toneladas de carga, en ese tiempo ya estaba especializado en el manejo de contendores en Sus Puertos de Manga donde está la Sociedad Portuaria Regional de Cartagena y a escasos metros de su sector industrial de Mamonal se encuentra el Puerto Contecar, ya por su dinamismo el Puerto de Cartagena varias navieras lo tomaron como Centro de Operaciones Logísticas o Zona de Apoyo Logístico. ZAL tiene en su historial varios reconocimientos como el de mejor Puerto del Caribe.

El puerto es receptor de más de 30 Líneas Navieras que son atendidas en Manga y Contecar. En más de 136 países y alrededor de 590 Puertos se interconecta con el mundo; lo que lo constituye en un Puerto de transbordo, se espera llegar a 
movilizar 5 millones de contenedores. Con sus 5 grúas súper postpanamax que llegaron al Puerto en el año de 2015, el 4 de agosto de las cuales 2 se quedan en Puerto de Manga y las otras tres van para Contecar, posteriormente, el 22 de abril del 2017 llegaron 6 grúas del mismo tipo, 4 para Contecar y 2 para Sociedad Portuaria.

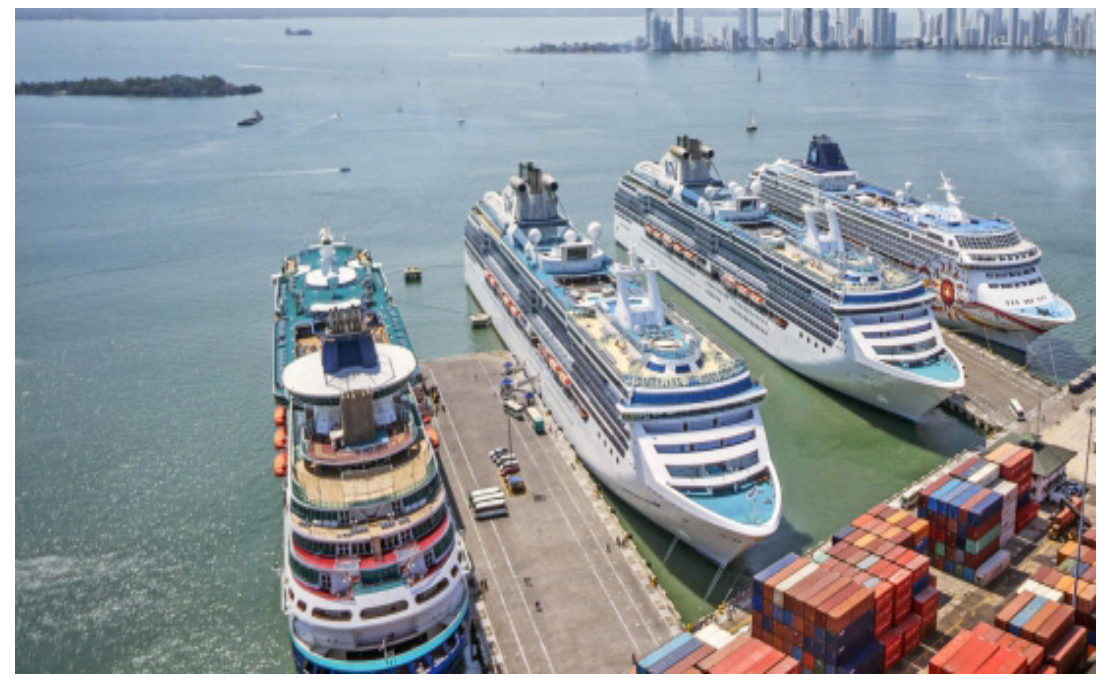

En la figura 4 ya arribó al Puerto de Sociedad Portuario Regional Cartagena, cuatro cruceros.

Figura 4. Arribo de cruceros y grúas pórticos al Puerto de Cartagena de Indias Fuente: Puerto Cartagena (2020)

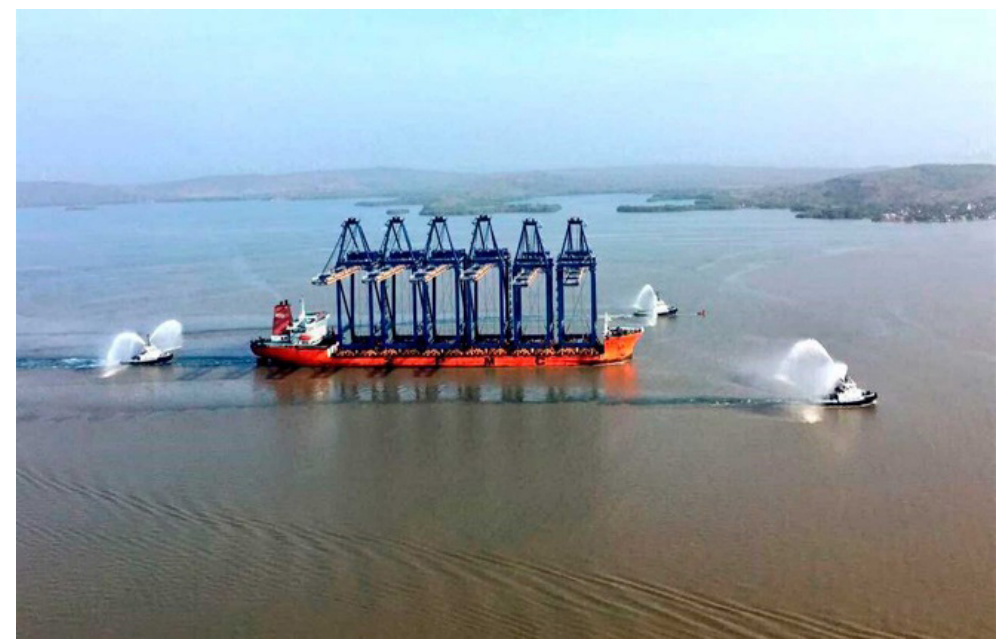

Figura 5. buque portando las grúas y entrado al Puerto de Cartagena. Nótese la escolta de los operadores prácticos. Fuente: Presidencia (2017)

Por eso los puertos se hacen sostenibles no sólo cuando son rentables sino cuando su dinámica hace que genere externalidades positivas en su entorno, y se necesita saber qué datos empíricos se presentan en la valoración de los Puertos, en materia de sostenibilidad, apoyo a sus moradores y su direccionamiento estratégico que jalone a la ciudad en que se encuentren ubicados.

\section{El Puerto de Callao}

Históricamente los Puertos han sufrido ataques de piratas como Francis Drake en el Callao, por otra parte, Vernón y Pointis saquearon al Puerto de Cartagena de Indias, aunque historiadores sostengan que no alcanzaron a llegar al Callao, otros sostienen que Francis Drake estuvo allá saqueando el Puerto en el año 1579 y posteriormente, el neerlandés Jacobo Clerck que lo hizo en el año de 1624 y otros estuvieron saqueando en Cartagena.

En la Provincia Constitucional del Callao llamada así está ubicado el principal puerto de Perú, 
ya que existen otros como: Paita, Matarani y Pisco; el Puerto de Callao moviliza más del $85 \%$ de mercancías del país Inca, está ubicado estratégicamente que le permite suplir las necesidades en gran parte del territorio nacional; tiene mucha tradición que lo une al Puerto de Cartagena y entre esas está las gestas de Independencia, siendo el año de 1821 cuando el general José de San Martín asedia a la fortaleza o Castillo en el mes de julio y durante el mes de agosto, hasta que en septiembre el mariscal José de La Mar capituló, posteriormente renunció a su condición de Mariscal y se unió a la Independencia del Perú en la Batalla de Ayacucho que le permitió más adelante la presidencia de la República del Perú, lo anterior corrobora a los Puertos de Cartagena y El Callao como protagonistas de la Independencia de América. En el año de 1866, el día 2 del mes de mayo, la Armada Española a cargo del almirante Casto Méndez Núñez, bombardeó al Callao, que estaba bajo el mando de Mariano Ignacio Prado quien ostentaba el honor de ser el Jefe Supremo de la República, como en toda historia cada quien la ve desde su óptica, España sostiene hasta la actualidad que sólo se causó daños menores y se retiraron, en el Callao se mantiene hasta hoy que se retiraron por la resistencia del Puerto y que se les acabó la munición a los atacantes españoles. El Puerto del Callao no sólo es el más importante del Perú, se considera como el más importante del Pacífico en América del Sur, ubicado al Oeste de la Ciudad de Lima, en el Perú, su construcción se estima que se hizo entre los años 30s y 50s del Siglo XX, en el ocaso de dicho Siglo prácticamente sucumbió, luego de 50 años operando, y fue retomado en concesión a partir del año 2011 por la empresa APM Terminals, la concesión será hasta el año 2041, entonces es el año 2011 como el año del hito en el Puerto de Callao, cons- truyó el Terminal Norte en Muelle multipropósito y comienzan a adquirir nuevos muelles y zonas de almacenaje, compra de maquinaria y equipos para su modernización; lo que conlleva al ensanche de su infraestructura portuaria y calidad de las maniobras logística portuaria, a través de sus operaciones en el Puerto.

Dos años después, es decir en el año de 2013 se contrató dos firmas: FCC Construcciones y JJC a manera de consorcio quienes llevaron a cabo un ensanche del Puerto con U\$ 206 millones, reforzaron los muelles 11 y 5 en más de 840 metros de longitud, para carga al granel y contenedorizada. El reto fue ampliar el patio de contendores en más de 157.000 metros cuadrados y un Edificio Inteligente para APM Colterminals y prestar servicios en el Puerto, además de la construcción de un edificio público y un centro recreativo. Ya en el año 2014 proyectaron con la adquisición de equipos duplicar el movimiento de contenedores. Las inversiones en frigoríficos multiniveles le permitió mover adicionalmente casi un millón de contenedores más y la infraestructura de entrada al Puerto de los camiones portacontenedores son vigilados por cámaras $11 \mathrm{R}$ de alta tecnología que les hace prácticamente una radiografía y monitoreo a la carga. Toda esa inversión se ha dado por el Consorcio FCC y JJC. Con la inversión en 4 grúas pórtico STS, Súper postpanamax y tiene 12 grúas de patio RGT Eléctricas; el Puerto también ha diseñado un sistema rápido de descarga de graneles en camiones a través de una especie de mega juppers o tolvas 3 que actúan como embudos para descargar la mercancía granelera, apoyados con 4 grúas móviles liebherr que facilitan la maniobra.

Tabla 1. La inversión en el puerto del callao

\begin{tabular}{lll}
\hline \multicolumn{1}{c}{ Etapa } & Grúas & $\begin{array}{c}\text { Movimiento en teus } \\
\text { anual }\end{array}$ \\
\hline Etapa 1 & 2 grúas pórticos, 2 grúas de patio RTGs & 1.214 .000 \\
Etapa 2 & 3 grúas pórticos, 6 grúas RTGs, 2 grúas móviles & 1.528 .000 \\
Etapa 3 & 3 grúas pórticos 26 grúas RTGs, 4 grúas móviles & 1.803 .000 \\
Etapa 4 & 9 grúas pórticos, 38 grúas RTGs, 4 grúas móviles & 2.287 .000 \\
Etapa 5 & 13 grúas pórticos, 46 grúas RTGs & 2.668 .000 \\
Etapa 6 & 15 grúas pórtico, 52 grúas RTGs, 4 grúas móviles & 2.737 .000 \\
Etapa 7 & 18 grúas pórtico, 57 grúas RTGs, 4 grúas móviles & 3.057 .000 \\
\hline & Fuente: El economista América (2020)
\end{tabular}

Vale la pena aclarar que se hará realmente según su planeación en 4 etapas, pero toman etapa 0 como inicial y en la etapa tres le dan 2 momentos y en la etapa 4 tres momentos. Son proyecciones que tiene el Puerto del Callao y que ha puesto a trabajar más rápido al Puerto de San Antonio 
en Chile que ha perdido el liderazgo en el Pacífico o Costa Oeste de América del Sur. El Puerto del Callao tiene 5 muelles, 4 son terminales y el quinto es multipropósito, cada uno de los muelles tiene dos amarraderos, pero el muelle Norte multipropósitos tiene 4 amarraderos. Al tener esa capacidad de movimiento de contenedores, necesitará más calado del muelle por lo que habrá que dragar a más de 16 metros para los mega portacontenedores y en el año 2019 con una inversión de U\$372 millones en el muelle para ampliar y fortalecer su infraestructura, le permitió atender en el año 2020 un buque con capacidad para 14.000 teus, el APL Splanade, Mundo Marítimo (2020).

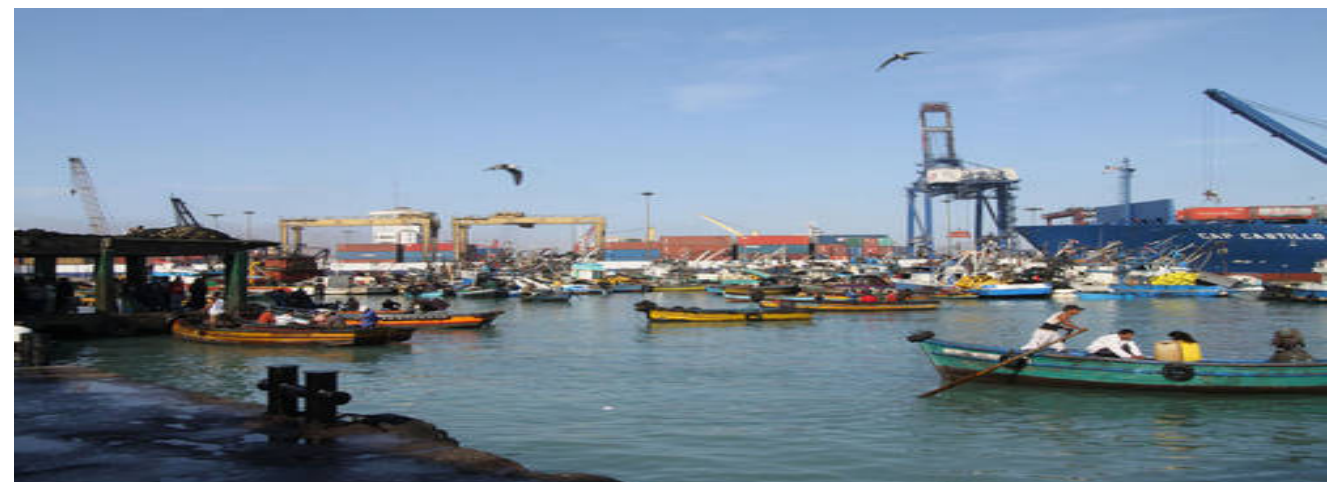

Figura 6. Imagen de pescadores en su faena del Puerto del Callao Fuente: Generación.com (2011)

Nótese que los pescadores hacen sus faenas en medio de las maniobras logísticas del Puerto, trayendo serios problemas de movilización aparente, pero en medio de todo han logrado convivir y evidencia que las aguas del Puerto no están contaminadas o vedadas para la pesca como si lo está el del Puerto de Cartagena de Indias en su Bahía desde el año de 1976, por otra parte, los pescadores del Puerto de Callao son alrededor de 2.200 que laboran desde hace más de 60 años.

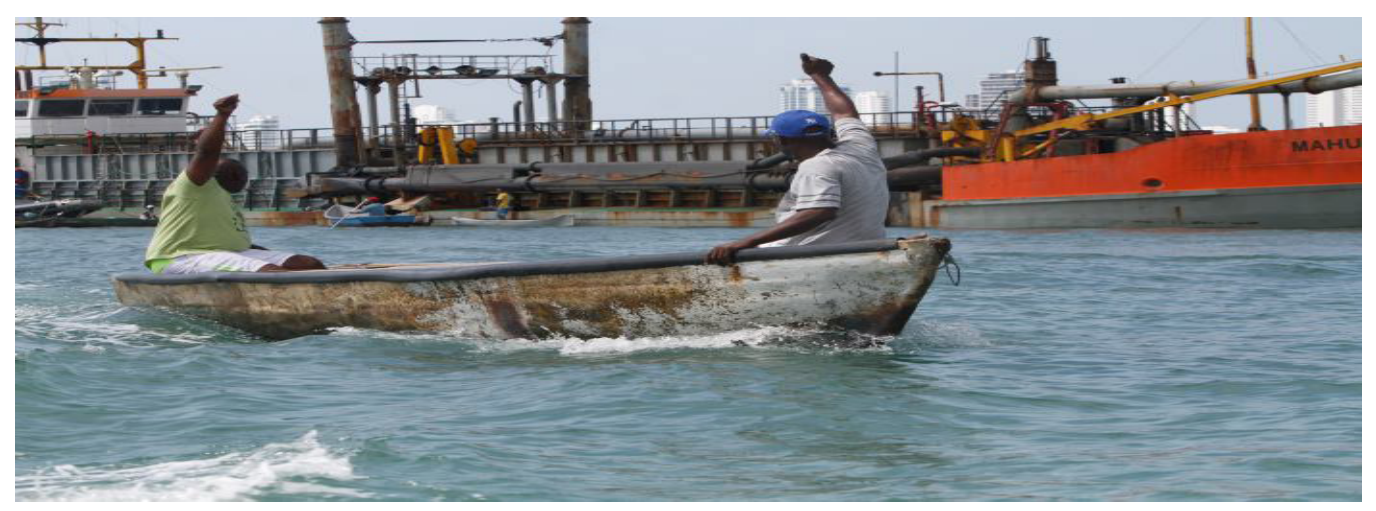

Figura 7. Pescadores en Cartagena de Indias protestan por el dragado de la Bahía Fuente: El Universal (2018)

El evento se dio por el dragado al Muelle de la Empresa Algranel S.A. en el año 2018, aducían que el lecho marino se acaba con el dragado y por ende la pesca, aunque está vedada desde el año 1976 en la Bahía de Cartagena de Indias.

\section{Referentes relacionados con los puertos de EI Callao y de Cartagena de indias}

En cuanto a estudios comparativos sobre Puertos, Boyano-Fram, T. O., \& Hernández-Co- bo, J. S. (2018). Señalan que un estudio hecho a los Puertos de Veracruz y el de Cartagena de Indias arrojó que entre sus hallazgos que de acuerdo con sus condiciones morfológicas el Puerto de Veracruz tiene ventajas por ser un Puerto natural y con gran inversión en su infraestructura, aunque el Puerto de Cartagena tiene grandes alianzas estratégicas que le favorecen para seguir creciendo en maniobras logísticas

Las operaciones portuarias necesitaban un cierto orden, al igual que lo que ocurría en el 
Puerto de Cartagena en los años 70s, 80s y a inicio del 90, por eso se hizo concesión para el Puerto del Callao en el Muelle Sur, como sostiene Rondan, H., Aguilar, J. C., \& Ortiz Ruiz, H. (2007) que señalan:

La concesión portuaria se otorgó bajo un sistema mono operador, lo que permitió al concesionario administrar la infraestructura y prestar los servicios relacionados con esta en forma exclusiva. De este modo, se buscaba hacer atractiva la concesión para un mayor número de postores y mejorar la eficiencia y la seguridad en las operaciones portuarias. (pág. 13)

Dada la lentitud o paquidermia en las maniobras logísticas se ha tenido que acudir al sistema en concesión para que se privatice la labor, pero el Puerto sigue siendo público, al igual que el Puerto de Cartagena que aunque se le ha dado la operación en concesión, lo que no ocurría antes para ambos puertos ya que antes de entrar a internacionalizarse el Puerto de Callao y ser más competitivo, tenía problemas en maniobras logísticas y hay un estudio que revela el cambio que se presentó en su gestión logística, Guibert, Y., Cruz, M., \& Figueroa, M. (2015) sostienen que el estado peruano tuvo que mejorar su infraestructura para ser competitivo internacionalmente y se modernizó para llegar a ser la plataforma logística más relevante de Suramérica en la Costa Pacífica y se corrobora su participación con el apoyo del gobierno en materia de impulso a la apertura comercial aunque con el reto de planificación a largo plazo; aunque sin lugar a dudas el cambio de paradigma de lo público a lo privado, al menos en concesión le ha dado al Puerto de Callao más ventajas competitivas al igual que al Puerto de Cartagena de Indias, pero se espera mejor gestión de lo público sobre el Puerto, ya que al darse en concesión, no significa que no se monitoree su gestión y se ha ido en detrimento de lo público, concretamente si impacta ambiental mente o si ha dado nuevos puestos de trabajo; otro aspecto que dan sinergia positiva al menos a los Puertos, según estudio realizado al Puerto de Callao y relacionado al transporte internacional hecho por Andrade Mimbela, C. A. (2015) sostiene que los países que abren sus mercados crecen en bienestar social pero se encuentran con el limitante de poca calidad en materia de infraestructura de las instituciones y la conquista de mercados que debilitan la competitividad por que se elevan impuestos que no logran darle ingreso adecuado a nuevos mercados; por lo que según el autor los puertos se abren al mercado para satisfacer la demanda internacional, pero retrasa toda la gestión en los Puertos la falta de una política adecuada que evite trámites aduaneros o documentos en la gestión portuaria, aunque se haya avanzado en planillas únicas, lo anterior se haría para evitar lo que se conoce como barreras no arancelarias, aunque la idea con los documentos aduaneros unificados entre Puertos deben estar incluidos en convenios a partir de Tratados de Libre Comercio.

En cuanto a la pobreza en los Puertos el del Callao está ubicado en el Perú en uno de los menos pobres, en contraste con el Puerto de Cartagena que tiene grandes retos en materia de desigualdad, unos residentes que no se concientizan que al turismo hay que atenderlo bien y se dan ciertos incidentes muy aislados, de turistas mal atendidos, por eso se propone una geoecología paisajística, que confluyan los usuarios del turismo, el servidor del turismo y un ambiente amigable, es por eso que en cuanto a la geoecología del paisaje en el Puerto El Callao, Herrera, V., \& Paul, H. (2012) señala que hay armonía entre el Puerto del Callao y la laguna de la ciudad, al mismo tiempo que si la intervención en materia paisajística es adecuada, entonces las zonas que lo integran proyectan al turismo internacional con su cultura, comercio y el mismo turismo generando mayor sostenibilidad a sus moradores apoyados en las tecnologías y la sistematización del Puerto y la urbótica o la automatización de la infraestructura en su entorno; lo anterior se ha logrado ya en el año 2019 muchos de esos aspectos se han desarrollado, más adelante se corrobora que bastante se ha avanzado en los últimos 8 años en cuanto al Puerto del Callao.

En lo que se refiere a inversiones en Infraestructura portuaria al 2006, año de inicio de las concesiones portuarias, se estimó un déficit de $\$ 695$ millones de dólares, la sustentación de los teóricos entre ellos (Gitman \& Zutter, Principios de Administración Financiera, 2012), señala que la "rentabilidad es la relación entre ingresos y costos generados por el uso de los activos de la empresa en actividades productivas" mencionar activos es señalar implícitamente inversión. Se ha operado con el programa estadístico EWIE, aplicando un modelo de serie de tiempo, evidenciando que los costos, ente otras variables es un factor de suma importancia para la rentabilidad del Puerto del Callao, consolidar el modelo de negocio portuario, Landlord Port, que implica mayor inversión y también reducción de costos en 
los puertos es a ciencia cierta el epilogo de este trabajo. Benavides Cabrera, F. R. (2019).

Por lo que la modalidad de Landlord Port hace de cualquier puerto sea más competitivo con inversión pertinente y liderazgo en costos. Hay otro estudio realizado en el Puerto del Callao que revela la vocación de mercancías transportada en contenedores y que ha crecido positivamente por los cambios que se están dando en la internacionalización del comercio. Condori Morales, G. (2017).

Los Puertos necesitan crecer y estar a la altura de los mercados internacionales que cada día se especializan más por las exigencias de las transnacionales, como señala Boyano-Fram, T. O. (2019)

Así como los Sistemas de Información y los buques o embarcaciones se van perfeccionando y facilitando la atención a los usuarios, de nada sirve si el Puerto como un todo, no está preparado para atender las exigencias del Mercado. El siguiente texto es el resultado de una revisión de la literatura relacionada con el tema, en el que se describe los Referentes relacionados con Puertos de Cuarta Generación, además se incluye los retos que tendrán que enfrentar en un país que no logra tener índices de Desarrollo Económico, en él se infiere que políticas públicas orientadas a fortalecer el Puerto a la altura de los más desarrollados será el camino de entrar en Puertos de Cuarta Generación. (pág. 72)

Los grandes avances en las tecnologías aplicado a las embarcaciones, el incremento en su volumen de carga pone a los gestores portuarios a ampliar sus instalaciones para satisfacer la demanda internacional de grandes volúmenes de carga.

En cuanto a otros aportes en materia logística, Fontalvo-Herrera, T., De-la-Hoz-Granadillo, E., \& Mendoza-Mendoza, A. (2019) presenta además un estudio sobre procesos logísticos y la cadena de suministro que sirven como aporte a la construcción del artículo, al igual que Balza-Franco, V., Paternina-Arboleda, C., \& Cardona-Arbeláez, D. (2019) abordan las prácticas colaborativas en la cadena de suministro. Lugo Arias, E. R., Sáenz Zapata, J. A., \& Lugo Arias, J. L. (2021) presentan un estudio sobre la gestión de la palma de aceite en el Magdalena que ilustra cómo se lleva a cabo y su relevancia comercial.

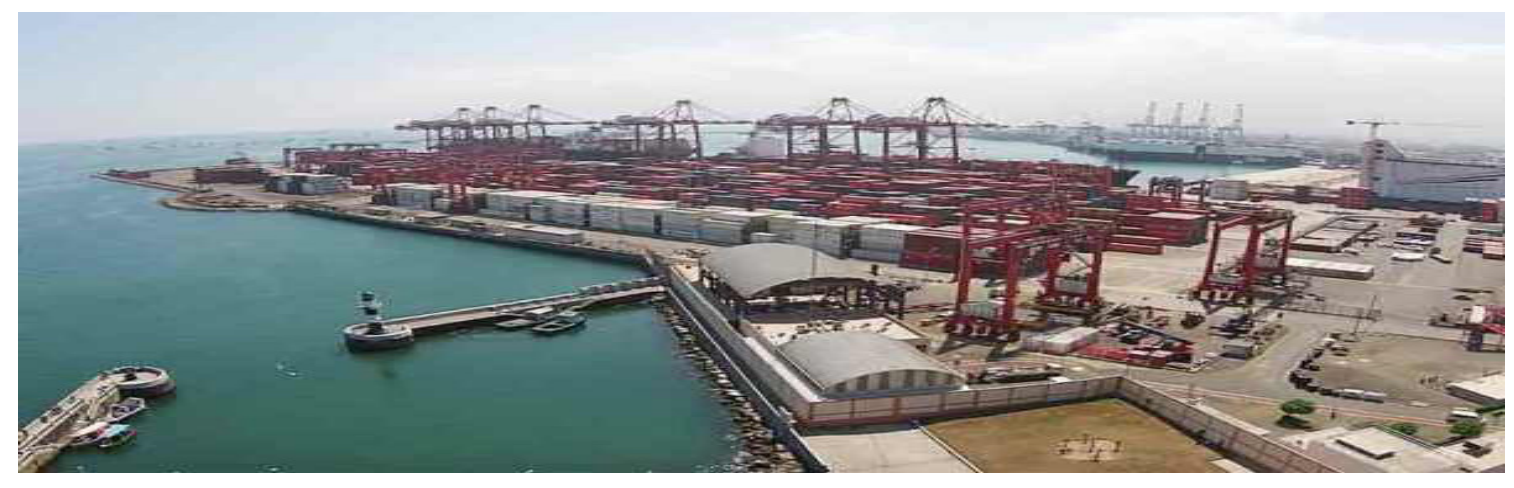

Figura 8. Panorámica del Puerto del Callao

Fuente: LogiNews (2020)

Nótese al Fondo el otro Muelle con sus grúas evidencia facilidad de manobras logísticas de y un gran patio de contenedores, la imagen acuerdo a la ubicación de los muelles.

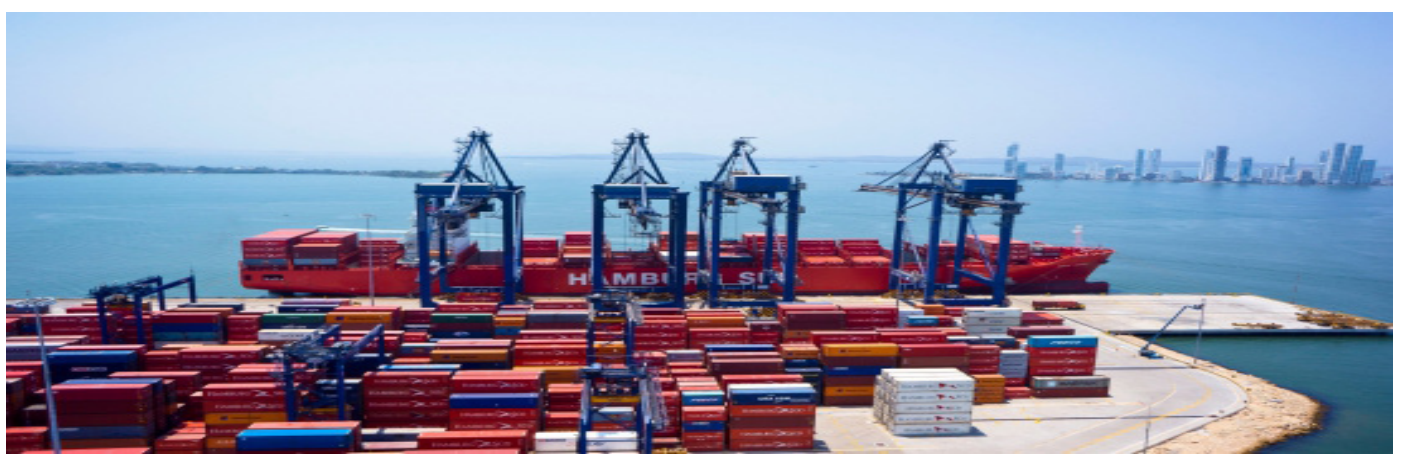

Figura 9. Panorámica del Muelle del Puerto de Cartagena de Indias Fuente: Grupo puerto de Cartagena (2020) 
Nótese al fondo la zona residencial a la derecha, a la izquierda la Bahía y zona del Bosque que es también zona de empresas relacionadas con el comercio y marítimo. El Puerto de Callao y el de Cartagena de Indias a partir de los últimos
10 años han hecho un gran viraje hacia la competitividad y comienzan a crecer y para muestra se hace un análisis comparativo de la siguiente manera:

Tabla 2. Datos comparativos de los puertos de El Callao y Cartagena de Indias

\begin{tabular}{|c|c|c|}
\hline $\begin{array}{l}\text { A s p e c to s } \\
\text { para valorar }\end{array}$ & Puerto del Callao & $\begin{array}{c}\text { Puerto de Cartagena de } \\
\text { Indias }\end{array}$ \\
\hline $\begin{array}{l}\text { Ubicación lo- } \\
\text { gística y ex- } \\
\text { tensión }\end{array}$ & $\begin{array}{l}12^{\circ} 03^{\prime} 37^{\prime \prime} \text { Latitud } \\
\text { Sur y } 77^{\circ} 08^{*} 57^{\circ} \\
\text { Longitud Oeste y } \\
\text { con } 145,91 \mathrm{~km} 2 \mathrm{de} \\
\text { los cuales } 17,63 \mathrm{~km} 2 \\
\text { son insulares }\end{array}$ & $\begin{array}{l}10^{\circ} 25^{\prime} 25^{\prime \prime} \text { Norte y } \\
75^{\circ} 31^{\prime} 31^{\prime \prime} \text { Oeste con } 609,1 \\
\mathrm{~km} 2,1811 \mathrm{hab} / \mathrm{km} 2\end{array}$ \\
\hline $\begin{array}{l}\text { Año de fun- } \\
\text { dación y fun- } \\
\text { dador }\end{array}$ & $\begin{array}{l}1537 \text { por Francisco } \\
\text { Pizarro }\end{array}$ & 1533 por Pedro de Heredia \\
\hline
\end{tabular}

Población y 1.000 .000 habitantes 1.036 .000 habitantes en su densidad en su área metropoli- área metropolitana tana con $8.908 \mathrm{hab} /$ $\mathrm{km} 2$

Nivel del mar 3 metros

1 metro

Infraestructu- 18 grúas pórtico, 5754 muelles y de ellos 18 ra portuaria grúas RTGs, 4 grúas móviles. Hay dos al comercio externo y 7,7 kilómetros cuadrados de grandes Terminales de Contenedores y pac son: El Terminal de mega porta contendores. 19 Contenedores Mue- grúas pórticos STS, 3 grúas lle Sur y el Terminal MHC con capacidad de 100 Norte Multipropósi- toneladas; 70 grúas RTGs, to del Callao. 2652 tomas para refrigeración y 228 tracto camiones, 18 carriles de acceso con tecnología OCR*

Pobreza $7 \%$ y más de 30 pandillas

\section{Características \\ Observaciones} y Por ubicación El Callao Puerto del Callao lidera tiene temperatura pro- las maniobras logístimedio de $23^{\circ}$ y Carta- cas en América del Sur gena está en promedio en el Oeste del Pacífico, en $29^{\circ}$, por los vientos mientras que el Puerto alisios logra llegar a 24, de Cartagena de Indias mientras que el Callao es el líder en el Caribe ha llegado a $13^{\circ}$.

Diego Ruiz es la prime- No hay una fecha exacra autoridad del Callao ta de la Fundación del Callao, algunos sostienen que fue en 1535

Cartagena de Indias Al ser el Callao una tiene influencia de su Provincia Constitucioárea metropolitana, nal se tiene datos no con población flotante exactos de población y de 100.000 temporada extensión. baja.

Cercanía y acceso a em- Ambos puertos son acbarcaciones cesibles a maniobras logísticas

El Puerto de Callao tieAmbos Puertos tiene ne dos grandes termina- otros Puertos en su enles, el del Sur y el del torno, pr esos son los Norte Multipropósito. que lideran el moviMientras que el de Cartagena quienes lideran el movimiento de contendores está SPRC y miento de Teus, Cartagena tiene más atracaderos y muelles que pasa de

Contecar.

Las pandillas no tienen Los Puertos aportan reincidencia directa en cursos para jóvenes en ambos Puertos riesgo y pescadores de la región. 


\author{
Movimiento 2.670.000 teus 5.000 .000 de teus \\ de contendo- aprox. \\ res
}

Incluye para Cartagena Aunque el Puerto de de Indias SPRC y Con- Cartagena mueve más tecar carga, la proyección del Puerto del Callao es que se acercará bastante en movimiento de Teus al de Cartagena.

Fuente: Elaboración propia del autor

Cartagena de Indias como ciudad portuaria, presenta los siguientes muelles: un muelle Público, más de 8 astilleros, 6 de carga contenedorizada y suelta, 10 de pesca, 5 de cabotaje, 1 de almacenaje, aunque la gran mayoría de muelles tiene sus patios para guardar la mercancía. Para recreación y turismo hay 6 , pero existen al menos 10 atracaderos entre Manga y Bocagrande e incluso en el Muelle de los Pegasos. 6 de productos químicos y 8 terminales graneleros, líquidos y uno cementero. La ciudad sigue creciendo, uniendo y saliendo entes relacionados con la logística portuaria de Cartagena de Indias, la globalización, las integraciones y alianzas que se hacen para aumentar presencia en la ciudad y el Caribe han permitido que crezca la oferta de servicios. Tanto el Callao como Puerto de Cartagena tiene astilleros navales, en el Callao es el Servicio Industrial de la Marina, que es vigilado y administrado por la Marina peruana y en Cartagena está Cotecmar que cumple las mismas funciones. Hay que anotar que a partir de la Ley 1 del 1991, o Estatuto Portuario se dio cambio de paradigma en la prestación de servicios portuarios y se privatizan o dan en concesión El Terminal Portuario que tenía Cartagena de Indias, y surgen otras Sociedades Portuarias y algunas ya se han anotado en este artículo; las principales Sociedades Portuarias de Cartagena de Indias están:

- Sociedad Portuaria Bavaria

- Ecopetrol SA. Cartagena

- Sociedad Portuaria Olefinas y derivados

- Puerto Mamonal

- Sociedad Portuaria Central Cartagena

- Exxon Mobil de Colombia

- Sociedad Portuaria Zona Franca Argos

- Terminal de Contendores de Cartagena. Contecar

- Vopap Colombia
- Compas SA.

- Sociedad Portuaria Algranel

- Sociedad Portuaria El Dique

- Chevron Exports S.A.S.

- Transmarsyp

- Puerto Buenavista

- Refinería de Cartagena

- Transpetrol

- Sociedad Portuaria Dexton

- Oiltanking Colombia

- Sociedad Portuaria Puerto Bahía

\section{Metodología}

Este artículo se hizo mediante la revisión bibliográfica y consulta de expertos relacionado con las maniobras logísticas portuarias, por lo que es de carácter hermenéutico, enmarcado en el paradigma y epistemología de las Ciencias Sociales, al mismo tiempo se toman algunos datos históricos y cuánticos por lo que es de corte mixto, teniendo en cuenta y analizando las variables sociales y económicas de los puertos.

\section{Resultados}

\section{Afinidades culturales de los puertos del Callao y Cartagena de indias}

"Por sus fiestas novembrinas y su santo San Martín llevamos alegría sin fin hasta sus playas marinas y en sus olas vespertinas se mira la mar serena luego la mujer morena por el camellón pasea y el negro que la desea así eres tú Cartagena": Pedro "Ramayá" Beltrán. Esa copla se canta mucho en Cartagena de Indias y refleja la alegría de la gente del Caribe, resalta las playas del mar en donde se practica en ella deportes náuticos como: 
el surf, cayac, pesca, buceo y navegación en botes de velas como catamaranes y windsurf, como en el Callao que al igual que en el Puerto de Cartagena se practica lo llamado trekking histórico, en Cartagena se le llama las rutas y las más novedosas están la Ruta museo para conocer todos los museos de la ciudad; la ruta de Gabriel García Márquez, Premio Nobel de Literatura que nació en Aracataca. Magdalena, pero vivió años de su juventud en Cartagena y también en sus últimos años especialmente en el Centro Histórico que le inspiró varias novelas. En el Callao residentes y visitantes también recorren sus calles del Centro y recuerdan leyendas y al tiempo que observan las casas, al igual que en Cartagena de Indias.

Como puertos se caracterizan por festivales que congregan a gente de todas partes, en el Ca- llao está el Festival Chim Pum con 24 años de música salsera, apreciada mucho y en él se ha presentado el Grupo Niche que les compuso una canción a Perú, la cual uno de sus versos dice: "Para mí no existirán males ni en mi alma pesares, al Callao llegaré para darte mis cantares" extraído de la canción "Me sabe a Perú" la cual menciona a Chim Pum, en Cartagena de Indias también se escucha y baila salsa, pero ha ido creciendo el baile de la champeta desde los años 80s; la salsa no obstante, tiene varios sitios donde se escucha y baila como; Quiebra canto, Vueltabajero, el Platanal de Bartolo y Donde Fidel que se ubica en el Centro Histórico, está cerrado en la actualidad La Esquina Sandiegana otro sitio icónico de la ciudad en el Centro Histórico en donde se escuchaba salsa.

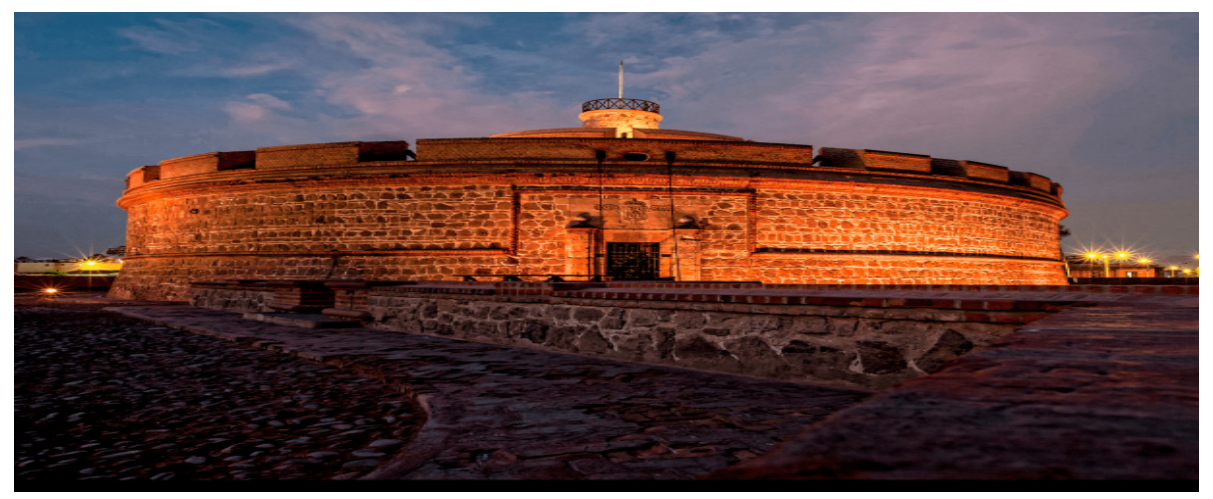

En Perú, específicamente en el Callao, entre los sitios de más atractivo turístico está la fortaleza del Real Felipe, considerada la única fortaleza en el Perú.

Figura 10. Fortaleza del Real Felipe

Fuente: Hotel LimaQ (2020)

Además del Museo Naval exhibe pinturas, reliquias navales y el Distrito de la Punta, con un gran malecón y vista

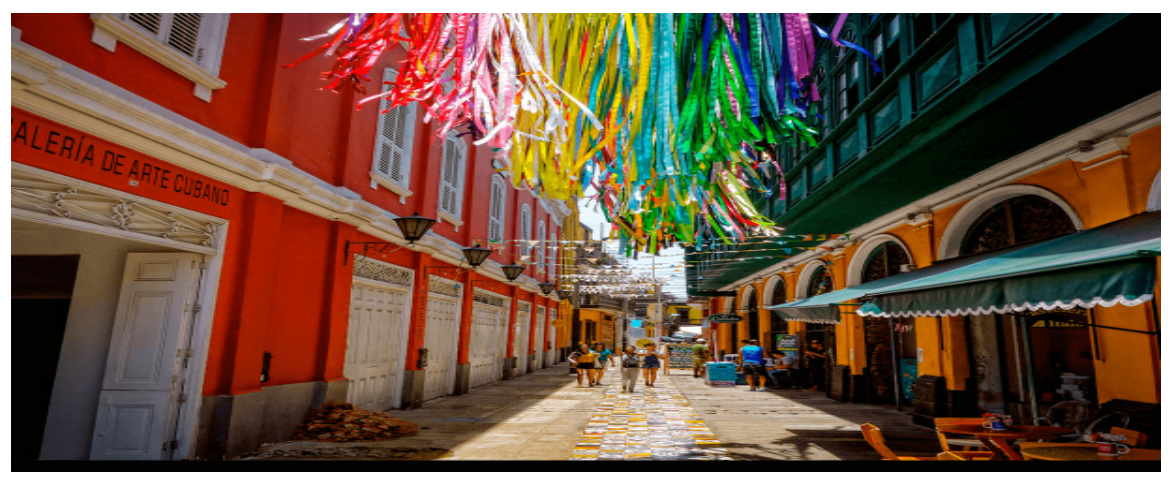

Figura 11. Centro Histórico del Callao Fuente: Hotel LimaQ (2020)

El tour a las 5 islas, las cuales son: isla Palo- prisión peruana, como la isla de Gorgona, en el mino, el Camotal, Cavinzas, el Frontón (antigua pacífico colombiano) y la isla San Lorenzo. 
En Cartagena de Indias también están los siguientes sitios turístico:

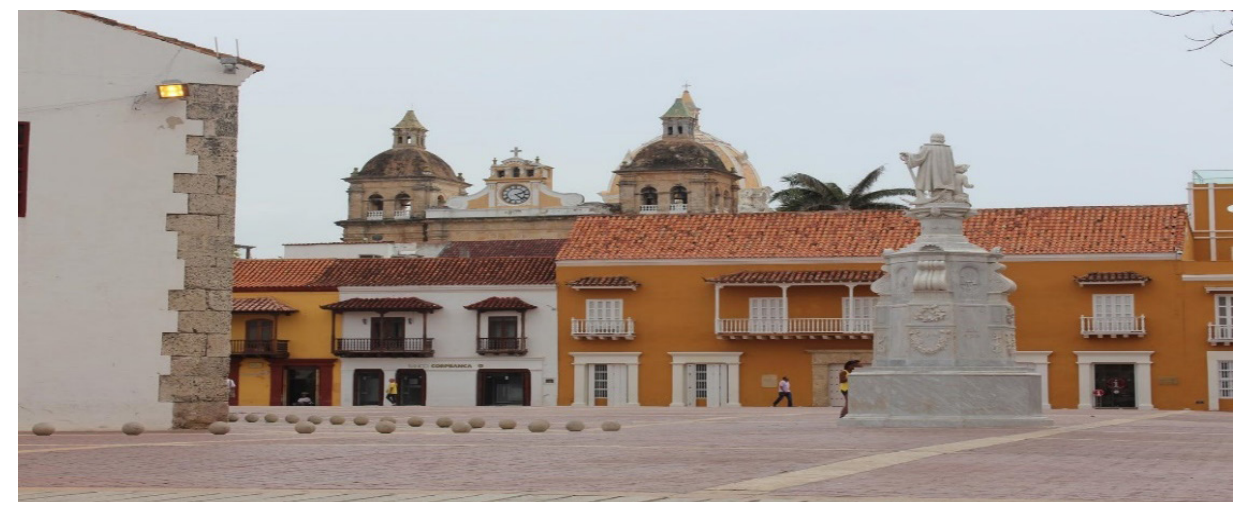

Figura 12. Plaza de la Aduana del Centro Histórico de Cartagena de Indias Fuente: Tripadvisor (2020)

El Centro Histórico de Cartagena tiene hoy día uno de los metros cuadrados más costosos de América, ya que sobrepasa los 5 millones de pesos según Alberto Calvo F (2020) en entrevista cualitativa. Los moradores se han preocupa- do por embellecer sus fachadas que seducen a propios y turistas, pero al mismo tiempo la valorización de los predios ha ido desplazando al cartagenero promedio hacia otras zonas.

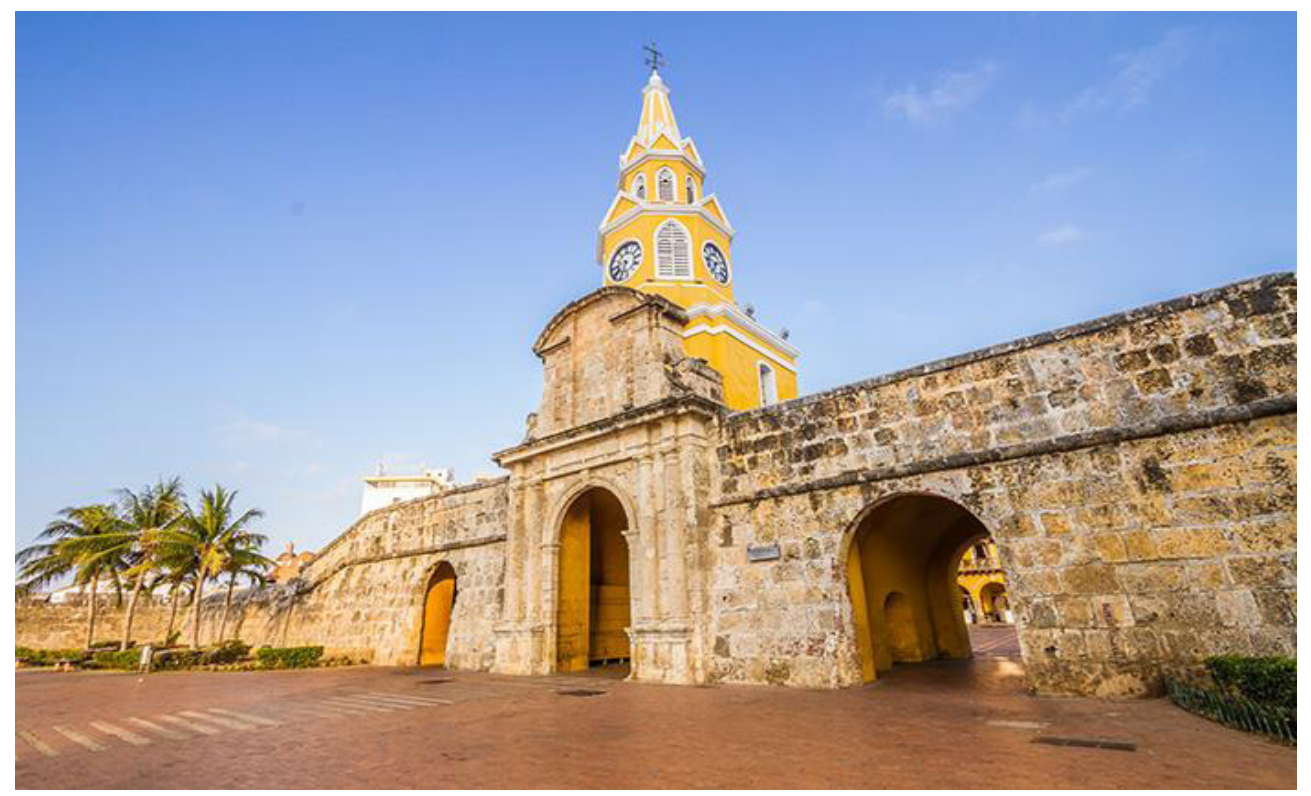

Figura 13. Reloj Público de Cartagena de Indias Fuente: Colombia.com (2019)

Otros escenarios culturales son el Barrio Getsemaní, en donde se inició la Independencia de Cartagena en el año de 1811 y la Avenida San Martín en Bocagrande. Paseo a las Islas de: Tierrabomba, Barú, Bocachica y Punta Arena; además del Archipiélago de San Bernardo, en donde están las Islas del Rosario. Se asemejan en el Museo Naval, calles llenas de leyenda, construidas en tiempos de la conquista, y arquitectura española, aunque el Callao está en el Pacífico y Cartagena en el Caribe, tienen como ciudades costeñas ese espíritu de alegría y diversión. Cartagena también tiene festivales gastronómicos como el del Pastel y el del Frito durante las Fiestas de la Candelaria, todos se hacen anualmente, también el Festival del dulce coincide con las Fiestas de la Semana Mayor o Santa.

\section{Resultados en materia de sostenibilidad}

Si bien es cierto los Objetivos de Desarro1lo Sostenible (ODS) se crearon en el año 2012, mediante la agenda de la Organización de las Naciones Unidas, tiene entre sus objetivos el de ciudades sostenibles, ese objetivo ha puesto 
a muchas ciudades del mundo como propósito alcanzarlos, en Colombia algunas ciudades han logrado préstamos de Findeter para proyectar a la ciudad a la altura de las mejoras ciudades del planeta, aunque su verdadera intención es el bienestar de La humanidad.

En contraste cuando se revisan los puertos ellos crecen en sus dinámicas y eso es muy positivo porque generan empleo, suplen necesidades e interconectan a las naciones y las empresas, en contraste están las ciudades portuarias, algunas crecen armónicamente, otras tiene grandes retos, por eso destacamos que entre los retos están que los problemas de inseguridad con las pandillas, aunque ellas no tienen injerencia directa sobre el turismo, dado que existe control que se ejerce sobre muchas de ellas, hay sitios que no pueden entrar los pandilleros; como también sitios de difícil acceso de las autoridades. En Colombia se le denomina a la mayoría como jóvenes en riesgo, en las ciudades portuarias de Cartagena de Indias y el Callao ponen fronteras invisibles, limitando a jóvenes a pasar de un sitio a otro, el Callao tiene menos pobreza al ser reconocida como Provincia Constitucional, aunque en los últimos 5 años se ha caracterizado por incremento en la inseguridad, atracos, robos y sicariato. Cartagena de Indias es Distrito Cultural y Patrimonio Histórico de la Humanidad desde mediados de los años $80 \mathrm{~s}$, el Callao tiene casi dos siglos de habérsele otorgado como Provincia Constitucional del Callao y se le llama la Perla del Pacífico, a Cartagena de Indias se le llama de Indias porque Cristóbal Colón creyó llegar a las Indias Occidentales y también para diferenciarlo de Cartagena España, se le llama Ciudad Heroica por la resistencia ante la Corona Española y por su gente que soporta adversidades políticas, muy pocas inundaciones en tiempos de lluvias e incidencia de huracanes en el Caribe, realmente ha sido muy esporádico. Fenalco, Cámara de Comercio y Funcicar, entre otras, son entidades que velan por la ciudad, las dos primeras por el comercio y los pequeños industriales, la tercera es un ente cívico que hace seguimiento a los políticos y la administración del municipio. La Cámara de Comercio de Cartagena, en el Callao está la Cámara Nacional del Turismo, la Autoridad Portuaria Nacional y el Plan Nacional de Infraestructura para la competitividad.
La movilidad es uno de los grandes retos a solucionar, mediante la Ley 30900 se creó la Autoridad de Transporte Urbano como ente que vigile y trate de regular los problemas que hay en materia de movilidad tanto para Lima como para El Callao que tiene entre sus principales vías a las Avenidas: Colonial La Marina y Sáenz Peña, al igual que el Puerto de Santos está el Ferrocarril Central que pasa por sus instalaciones y canaliza minerales provenientes de la zona minera de Perú. En Cartagena de Indias la construcción del Sistema Integrado de Transporte Masivo, Transcaribe ha ayudado en materia de movilidad acortando las distancias por el solo bus, aunque existe un desorden administrativo en materia de movilidad, y aunque en Cartagena de Indias está el Datt o Departamento Administrativo de Tránsito y Transporte, no alcanza a mitigar la movilidad de la ciudad, faltan más Agentes de Tránsito y a la fecha se le había autorizado a la Policía Nacional apoyar y vigilar la movilidad, según el Código Nacional de Tránsito y Transporte; el Corredor de Carga que pasa por Sociedad Portuaria Regional Cartagena y más adelante por Contecar hacia la Zona de Mamonal y a la Variante de Gambote permite que se aumente el flujo de mercancías de salida e ingreso al Puerto.

\section{Conclusiones}

El puerto de Callao emplea a más del 95\% del talento humano local; generando un impacto positivo en la zona, actualmente tiene 3 operadores que son: DP World Callao, Transportadora Callao y APM Terminals quien es el principal operador en concesión. Los Puertos han sufrido de la contaminación de los ríos, en el Perú, el Rio Rímac, que arrastra toda clase de sedimentos, algunos químicos asociados a la agricultura, en Cartagena también y por el brazo del Canal del Dique han llegado muchos sedimentos, casi colmatando la Bahía, por eso se le han hecho estudios y algunas obras civiles de mitigación, específicamente dragados y se hará una obra de ingeniería al Canal del Dique para frenar los sedimentos a la Bahía; ambas ciudades portuarias han sufrido la contaminación con algunos accidentes, ya sea por descuido o negligencia que han llevado a derrames de combustibles y petróleo. Aunque se dio principalmente en los años 70 s a fines de esos años y muy esporádicamente se han presentado incidentes de derrames $o$ 
vertimientos de la zona industrial de Mamonal, la pesca está vedada en la Bahía de Cartagena desde el año de 1976. En el Callao gracias a las medidas sanitarias, el seguimiento a las embarcaciones y el cuidado del Rio Rímac ha permitido que se pesque, aunque tiene problemas porque en ocasiones están muy cerca de las embarcaciones que operan sus maniobras logísticas en el Puerto, los chalanitas, así les llaman a los botes pequeños que en Cartagena se les llama chalupas, son las que ocasionan problemas, ya que dejan amarrados muy cerca a la playa sus embarcaciones. Los Puertos siguen creciendo en maniobras logísticas, pero con grandes retos contra la pobreza y el pandillismo, ya que si se suman las pandillas que están en las dos ciudades portuarias superan hace varios años el centenar. La principal causa del poco acceso a vivienda propia es el encarecimiento del suelo, el aumento de la población en Cartagena por efectos migratorios relacionados con el conflicto interno, aunque ya bastante disminuido por el Acuerdo de paz, además del desplazamiento natural buscando nuevas oportunidades como ciudad turística, también por problemas de calidad de vida en otros municipios y departamentos, ha permitido que se duplique la población en los últimos 20 años. Cartagena de Indias está en mora para la construcción de su Ferrocarril que movilice la carga granelera y lo conecte con la zona minera del país.

El Callao tiene mejor calidad de agua en su Puerto, aunque pocos son los turistas que no les gusta el acceso al Puerto por sensación de inseguridad, una vez entran a la zona portuaria cambia su percepción, el Puerto de Cartagena por efectos de la gran sedimentación proveniente del Rio Magdalena a través del Canal del Dique y la contaminación accidental de fluidos vertidos a la Bahía ya comentado; además que presenta menos vertimientos de aguas servidas en sus cuerpos o espejos de agua. La pesca de mar abierto si es apta para el consumo por que cambia las condiciones a escasos minutos de salir de la Bahía. Más de $80 \%$ de los porteños tienen vivienda independiente, se la hace monitoreo a servicios públicos y la calidad de los gobernantes, mientras que en Cartagena de Indias entidades ambientales vigilan calidad del agua, pero en lo relacionado a cuerpos de agua se ha avanzado significativamente con emisarios submarinos. Cartagena tiene y se reitera que en su sector inmobiliario un gran reto, ya que es muy costosos tener vivienda, motivo por el cual la ciudad ha empezado a ordenarse hacia el Nororiente y el Sur. Perú ha avanzado en gran manera a su crecimiento debido a que no tiene conflicto interno y una clase política que se ha ido poco a poco depurando, hasta el punto de que su último presidente, Pedro Pablo Kuczynski renunció por escándalos de presuntos sobornos recibidos de una multinacional. En la actualidad Martín Vizcarra regenta la presidencia. Porteños o chalacos es como se les denomina a los que nacieron y viven en el Callao, ya que se considera que Callao es o significa piedras. Con 184 años de ser autónomo desde el año 1836 desde agosto 20; en la actualidad Alarcón Ponce, P. C., \& Ordoñez Morales, A. K. (2020) tiene un estudio sobre la vocación importadora del Puerto del Callao; mientras que Loo Vilchez, D., \& Mariátegui Villafani, R. L. (2020) abordan el tema de modernidad del Puerto y su digitalización en materia aduanera y Torres, V. L. P. (2020) lo hace desde la calidad del servicio de la autoridad marítima nacional en el Callao.

Cartagena de Indias es Patrimonio Histórico de la Humanidad según la Unesco desde el año de 1984 y en el año de 1991 es Distrito Turístico y Cultural, en contraste la ciudad tiene problemas serios de gobernabilidad y por ende no puede cumplir sus planes de desarrollo. Jiménez, J. A. M. (2017). No obstante, los descuentos que han hecho para el pago de impuestos de valorización y el predial ha permitido ingresos al erario público para hacer mejoras en sus vías y sanear barrios y localidades. Al cierre de este artículo se ha perdido para la ciudad más de 50 millones de dólares que es lo que deja el turismo de cruceros en Cartagena de Indias por efectos del covid 19, los comerciantes, los guías turísticos y todos los que hacen parte de la cadena logística en la atención a cruceristas sufre una gran depresión económica. Los barrios con más carencia son los de la falda de la Popa y los aledaños a la Ciénaga de la Virgen. Pérez, G., \& Salazar, I. (2007); la situación es de retos, de innovar por que las microempresas del Centro Histórico no pueden laborar como antes y la afluencias al Centro Histórico de los moradores de Cartagena prácticamente es muy limitada, la ciudad depende mucho de su Centro Histórico, a pesar de la desconcentración de entidades públicas y las Corporaciones Financieras y comer- 
ciales que se han ido desplazando a otros polos de desarrollo, la tradición de llegar al Centro Histórico en sus moradores espera reactivarse cuando pase la pandemia; mientras el Puerto de Cartagena crece y mitiga los problemas sociales a través de su Fundación Puerto de Cartagena, el Puerto del Callao mueve el $80 \%$ de la carga contenedorizada del Perú.

\section{Recomendaciones}

Revisar las Políticas Públicas en materia de seguridad en ambos Puertos ante los problemas del narcotráfico, específicamente en su entorno, ya que en su interior tiene drásticas medidas de seguridad, apoyado en tecnologías de punta.

\section{Referencias}

Alarcón Ponce, P. C., \& Ordoñez Morales, A. K. (2020). Determinantes que influyen en el uso del despacho anticipado de importación en el puerto del Callao en el período 2015-2019.

Andrade Mimbela, C. A. (2015). Gestión logística en las operaciones del transporte internacional para el desarrollo del comercio en el Puerto del Callao. Trabajo de Grado. Lima, Perú

Balza-Franco, V., Paternina-Arboleda, C., \& Cardona-Arbeláez, D. (2019). Prácticas Colaborativas en la Cadena de Suministro: Una Revisión Conceptual. Saber, Ciencia Y Libertad, 14(2), 77-101. https://doi.org/10.18041/2382-3240/saber.2019v14n2.5882

Benavides Cabrera, F. R. (2019). Factores determinantes de la rentabilidad en el Puerto del Callao 2006-2015. Universidad Nacional del Callao. Perú

Boyano-Fram, T. O. (2019). Retos logísticos de puertos de cuarta generación diagnóstico y modernización en países emergentes. Revista científica anfibios, 2(1), 72-82.

Boyano-Fram, T. O., \& Hernández-Cobo, J. S. (2018). Análisis comparativo de la logística sostenible entre el Puerto de Veracruz en México y el Puerto de Cartagena de Indias. Revista científica anfibios, 1(1), 19-31.

Cartagenadeindiasweb.com (2011). Mi Cartagena de Indias. http://www.cartagenadeindiasweb.com/cartagena_notas_invasion.html

Cepal (2018). Informe de la actividad portuaria de América Latina y el Caribe 2018. https://www.cepal.org/es/notas/informe-la-actividad-portuaria-america-latina-caribe-2018

Colombia.com (2019). Torre del Reloj. https://www.colombia.com/turismo/sitios-turisticos/cartagena/atractivos-turisticos/sdi463/124754/torre-del-reloj

Condori Morales, G. (2017). Análisis de sensibilidad del tráfico de carga de mercadería contenerizada en el puerto del Callao en relación al crecimiento del Comercio Exterior 2014. UNAS. Perú

El economista América (2020). Muelle Sur: ampliación demandará inversión superior a US\$ 300 millones. https://www.eleconomistaamerica.co/economia-eAm-peru/noticias/10384183/02/20/Muelle-Sur-ampliacion-demandara-inversion-superior-a-US-300-millones.html

El Universal (2018). Pescadores protestan por dragado en la bahía. https://www.eluniversal.com.co/cartagena/pescadores-protestan-por-dragado-en-la-bahia-270078-HCEU384164

Fontalvo-Herrera, T., De-la-Hoz-Granadillo, E., \& Mendoza-Mendoza, A. (2019). Los Procesos Logísticos y La Administración de la Cadena de Suministro. Saber, Ciencia Y Libertad, 14(2), 102-112. https://doi.org/10.18041/2382-3240/saber.2019v14n2.5880

Generación.com (2011). Tsunami: Pescadores artesanales del Callao en peligro por ampliación de la entrada al puerto. http:/www.generaccion.com/usuarios/54252/tsunami-pescadores-artesanales-callao-peligro-por-ampliacion-entrada-al-puerto 
Grupo puerto de Cartagena (2020). Bahía de Cartagena. https://www.puertocartagena.com/es/bahia-de-cartagena

Guibert, Y., Cruz, M., \& Figueroa, M. (2015). La modernización del puerto del Callao: La respuesta del Estado a la ola exportadora 2004-2011. Revista de Ciencia Política y Gobierno, 2(4), 101 127.

Herrera, V., \& Paul, H. (2012). Reestructuración urbano paisajista en la localidad de Puerto CallaoDistrito de Yarinacocha, departamento de Ucayali. Perú

Hotel LimaQ (2020). Los mejores 5 destinos turísticos del Callao. www.hotellimaq.com/blog/los-mejores-5-destinos-turisticos-del-callao/

Jiménez, J. A. M. (2017). ¿Sirven los planes de desarrollo en Cartagena de indias para gobernar, cuando hay alcaldes mayores inestables en el cargo? Gerencia Libre, 3, 46-54. Colombia.

LogiNews (2020). El puerto de Callao prevé un descenso del 20\% en la entrada de cargas. https://noticiaslogisticaytransporte.com/logistica/24/03/2020/el-puerto-de-callao-preve-un-descenso-del20-en-la-entrada-de-cargas/149074.html

Loo Vilchez, D., \& Mariátegui Villafani, R. L. (2020). Digitalización del proceso aduanero y su relación con la operatividad aduanera del puerto del Callao durante el periodo 2016-2020.

Lugo Arias, E. R., Sáenz Zapata, J. A., \& Lugo Arias, J. L. (2021). La productividad como determinante de la competitividad de las exportaciones de aceite de palma del departamento del Magdalena Colombia, 2007-2015. Saber, Ciencia Y Libertad, 13(1), 145-163. https://doi.org/10.18041/23823240/saber.2018v13n1.2088

Meisel-Roca, A. (1999). Cartagena 1900-1950: a remolque de la economía nacional. Cuadernos de Historia Económica y Empresarial; No. 4. Colombia

Mundo Marítimo (2020). El Puerto de Callao en Perú registró inversión por U\$372.millones. https://www.mundomaritimo.cl/noticias/

Pérez, G., \& Salazar, I. (2007). La pobreza en Cartagena: un análisis por barrios. Documentos de trabajo sobre economía regional, 94 . Colombia.

Presidencia (2017). Llegan 6 modernas grúas pórtico al Puerto de Cartagena. http://es.presidencia.gov.co/noticia/170428-Llegan-6-modernas-gruas-portico-al-Puerto-de-Cartagena

Puerto de Cartagena (2020). Terminal de cruceros. https:/www.puertocartagena.com/es/terminal-de-cruceros

Revista Contestarte (2017). El Tren de Calamar y su ruta a Cartagena de Indias. https://revistacontestarte.com/el-ferrocarril-de-cartagena-a-calamar/

Rondan, H., Aguilar, J. C., \& Ortiz Ruiz, H. (2007). La concesión del Muelle Sur del Puerto del Callao: una buena propuesta. http://repositorio.pucp.edu.pe/index/bitstream/handle/123456789/47301/rondan.pdf

Scadta (1928). La península de Icacos. https://www.fundcolomboalemanabaq.org/scadta

Torres, V. L. P. (2020). Gestión administrativa y calidad del servicio de la Autoridad Marítima Nacional según el usuario en el puerto del Callao. Revista de la Escuela Superior de Guerra Naval, 17(1), 09-26.

Tripadvisor (2020). Lugares históricos en Cartagena. https://www.tripadvisor.co/Attractions-g297476-Activities-c47-t17-Cartagena_Cartagena_District_Bolivar_Department.html 